(2) Open Access Full Text Article

REVIEW

\title{
Circadian rhythms in cognitive performance: implications for neuropsychological assessment
}

This article was published in the following Dove Press journal:

ChronoPhysiology and Therapy

14 December 2012

Number of times this article has been viewed

\author{
Pablo Valdez \\ Candelaria Ramírez \\ Aída García \\ Laboratory of Psychophysiology, \\ School of Psychology, University \\ of Nuevo León, Monterrey, Nuevo \\ León, México
}

Correspondence: Pablo Valdez Laboratory of Psychophysiology, School of Psychology, Universidad Autónoma of Nuevo León, Mutualismo I I0, Col Mitras Centro, Monterrey, Nuevo León 64460, México

Tel +528183483866

Fax +528183337859

Email valdez.pa@gmail.com

\begin{abstract}
Circadian variations have been found in human performance, including the efficiency to execute many tasks, such as sensory, motor, reaction time, time estimation, memory, verbal, arithmetic calculations, and simulated driving tasks. Performance increases during the day and decreases during the night. Circadian rhythms have been found in three basic neuropsychological processes (attention, working memory, and executive functions), which may explain oscillations in the performance of many tasks. The time course of circadian rhythms in cognitive performance may be modified significantly in patients with brain disorders, due to chronotype, age, alterations of the circadian rhythm, sleep deprivation, type of disorder, and medication. This review analyzes the recent results on circadian rhythms in cognitive performance, as well as the implications of these rhythms for the neuropsychological assessment of patients with brain disorders such as traumatic head injury, stroke, dementia, developmental disorders, and psychiatric disorders.
\end{abstract}

Keywords: human circadian rhythms, cognitive performance, neuropsychological assessment, attention, working memory, executive functions

\section{Introduction}

Human beings exhibit oscillations in their physiology known as biological rhythms. These rhythms are classified according to their frequency into circadian (one cycle per day), ultradian (more than one cycle per day), and infradian (less than one cycle per day). Circadian rhythms have been found in almost all human functions, including body temperature; the secretion of practically all hormones; cardiac, pulmonary, and metabolic activity; nervous system activity; and sleep-wake cycle. ${ }^{1}$ Circadian variations have also been found in subjective alertness and sleepiness. During the daytime, alertness is high and sleepiness is low, whereas the opposite occurs during the night-time. Circadian variations have also been found in the performance of many different tasks, such as sensory, ${ }^{2}$ motor, ${ }^{3}$ reaction time, ${ }^{4}$ time estimation, ${ }^{5,6}$ memory tasks, ${ }^{7,8}$ verbal tasks, ${ }^{9}$ arithmetic calculations, ${ }^{10}$ and simulated driving tasks. ${ }^{11}$ Performance increases during the day and decreases during the night. ${ }^{12-14}$ Performance also depends on a homeostatic process that involves a decay in execution with time awake (sleep deprivation), whereas sleep restores performance. ${ }^{15}$ Variations in human performance may be the result of circadian rhythms in cognitive processes that are crucial for the execution of all tasks. Rhythms in cognitive performance have been found for three basic neuropsychological processes (attention, working memory, and executive functions), which can modulate the execution of many tasks. 
Circadian variations in cognitive performance suggest that results in tests used for neuropsychological assessment vary at different hours of the day. In this paper, the recent results on circadian rhythms in human cognitive performance are reviewed, as well as the implications of these rhythms in the neuropsychological assessment of healthy subjects and patients with brain disorders.

\section{Methods used to assess circadian rhythms in performance}

Three methods have been used to study circadian rhythms in performance: a time of day protocol, a constant routine protocol, and a forced desynchronization protocol. A time of day protocol involves the assessment of performance two or more times during the day while individuals carry out their personal and social activities and without interfering with their sleep-wake cycle. ${ }^{10} \mathrm{~A}$ time of day protocol has produced mixed results, with some tasks showing best performance in the morning, and others in the afternoon or the evening. Contradictory results have been found. Peak performance of the same task occurs at different times of day in various studies. ${ }^{12}$ The variability in results with this protocol may be due to the fact that several conditions that modify circadian rhythms are not controlled, such as light, temperature, food intake, and physical activity.

A constant routine protocol consists of keeping stable all the conditions that may influence circadian rhythms, ${ }^{16}$ so room temperature, light intensity, and caloric intake are kept constant, the level of motor activity is reduced and maintained constant, and participants are kept awake. Performance is assessed at regular intervals (every 1 or 2 hours) for more than 24 hours. In studies where a constant routine has been used, performance in all the tasks is high during the daytime and low at night-time. ${ }^{14}$

In a forced desynchronization protocol, participants are required to adhere to a sleep-wake cycle with a period outside the entraining range of circadian rhythms (28 hours, for example). This condition produces a desynchronization between the sleep-wake cycle and the circadian rhythm in body temperature, because the latter continues to oscillate with a period close to 24 hours. Performance measurements are made at different times of the subjective day, when individuals are awake, so performance is assessed at different phases of the circadian rhythm of body temperature. ${ }^{17}$ In studies with a forced desynchronization protocol, performance correlates with the body temperature rhythm. Best performance occurs when the body temperature is high, and worse performance occurs when the body temperature is low. ${ }^{18}$ Circadian rhythms in physiology and performance are similar when recorded with a constant routine protocol or a forced desynchronization protocol. ${ }^{19}$ These two protocols are considered the best methods to assess circadian rhythms in cognitive performance. ${ }^{20}$ Despite the limitations of the time of day protocol, it is useful to show some evidence of rhythms of performance when it is not feasible to control the environment, such as working conditions or clinical settings.

\section{Theories of circadian rhythms in cognitive performance}

Kleitman ${ }^{21}$ proposed that oscillations in performance are due to the rhythm in body metabolism assessed through body temperature. Correlations between the rhythm in temperature and rhythms in performance have generally been found. ${ }^{4}$ However, there are differences in the phase between the rhythms; performance tends to be phase delayed in respect of the rhythm in body temperature. ${ }^{4,9}$ Also, circadian variations have not been found in the performance of some tasks. ${ }^{10,22}$ According to Borbély, ${ }^{23}$ performance depends on the interaction of two mechanisms: a circadian clock and a homeostatic process. The circadian clock produces oscillations in performance with a period close to 24 hours, whereas the homeostatic process produces a gradual decay in performance with time awake. Sleep deprivation worsens performance, whereas sleep improves performance. Other conditions that may change performance during the day are a 90-minute ultradian cycle in alertness, ${ }^{24}$ sleepiness occurring immediately after awakening from sleep ("sleep inertia"), ${ }^{25}$ and a post-lunch dip in alertness. ${ }^{26}$

\section{Circadian rhythms in subjective alertness and sleepiness}

Subjective alertness and sleepiness are modulated by time awake and circadian rhythms. Alertness declines and sleepiness rises as time awake increases. On the other hand, both variables correlate with the rhythm in body temperature. Alertness correlates positively with body temperature, and sleepiness correlates negatively., ${ }^{4,27}$ So, alertness increases during the daytime and decreases during the night-time, whereas the opposite occurs for sleepiness. ${ }^{26}$ It is very important to keep in mind that subjective alertness and sleepiness are self-reports of people's inner feelings. According to common-sense intuition, people attribute a causal effect to these subjective sensations. They assume that their activities (working or studying) are affected by how alert or sleepy they feel. But it is necessary to examine what physiological or cognitive conditions underlie these self-reports. When people report their subjective state, they may be detecting some 
physiological conditions, their capacity to process information, or their response capacity. The chain of events in the organism may run in reverse order. First, the internal physiological conditions are modified (body temperature drops); second, the capacity in cognitive processes diminishes; and, third, the person perceives these changes as a reduction in alertness or an increase in sleepiness. In summary, the biologic clock modulates body metabolism and cognitive performance, which changes the execution of many tasks, as well as subjective alertness and sleepiness.

\section{Circadian variations in performance of different tasks}

Circadian variations have been found in the performance of many tasks. Visual and auditory thresholds show changes with time of day. People detect changes in luminosity more easily in the evening, compared with the morning. ${ }^{28}$ Detection of two separate sounds was also better in the evening. ${ }^{2}$ Circadian variations have been documented in the perception of time. Individuals estimate more accurately a 10-second interval during the afternoon and evening (13:00-21:00) compared with at 09:00. ${ }^{6}$ Execution in a simple motor task is worst at night (04:00), ${ }^{3}$ and handwriting speed is also lower during the night (03:00). ${ }^{29}$ Circadian variations in reaction time have been documented in many studies. Best performance occurs in the evening, and worst performance occurs in the night and first hours of the morning. ${ }^{14,30}$ Reaction time correlates with the circadian rhythm of body temperature in such a way that performance increases when temperature is higher, and decreases when temperature is lower. ${ }^{4}$ The speed of processing information also shows circadian variations with a similar time course. ${ }^{31}$ Time of day differences in memory tasks have been found. Short-term memory decays from 08:00 to 20:00, whereas performance in a long-term memory task is lower at 04:00 than at 20:30 with a time of day protocol. ${ }^{7}$ Verbal reasoning exhibits a period of around 24 hours with a forced desynchronization protocol, and performance in this task correlates with the rhythm in body temperature. ${ }^{32}$ Arithmetic calculations also show circadian variations. Individuals carry out a greater number of additions per minute at 21:00 in a time of day protocol. ${ }^{10}$ Performance on a simulated car-driving task also shows circadian variations. The worst performance occurs at night. ${ }^{11,33}$

\section{Circadian rhythms in basic neuropsychological processes}

As mentioned in the previous section, circadian variations have been found in many tasks. These results suggest the possibility that oscillations in metabolism modulate the activity of specific brain areas, which, in turn, affect one or several basic neuropsychological functions such as attention, working memory, or executive functions. ${ }^{18,34,35}$ These three functions may impact the performance of a great number of tasks. Each one of these neuropsychological processes comprises several components, so it is necessary to analyze circadian variations in each component of these processes.

\section{Attention}

Attention is a neuropsychological process that involves the capacity to react to the environment and to select a sensory signal and a specific response, as well as the capacity to maintain responses over time, guiding all behavior, including language and thinking. ${ }^{36}$ Attention comprises four components: tonic alertness, phasic alertness, selective attention, and sustained attention. ${ }^{27,36,37}$ Tonic alertness is the capacity to respond to the environment at any moment, phasic alertness refers to the capacity to respond to a stimulus after a warning signal, selective attention is the capacity to respond to a specific stimulus while not responding to other stimuli, and sustained attention is the capacity to respond efficiently to the environment during prolonged periods (from minutes to hours). Three cerebral systems are involved in attention: the reticular system, the prefrontal system, and the parietal lobe. ${ }^{38}$ The reticular system is related to the level of tonic alertness, the prefrontal system selects and sustains the activity related to a goal, and the parietal lobe directs attention to specific space locations. ${ }^{39}$

Many researchers have proposed that circadian rhythms modulate the general level of alertness (tonic alertness). ${ }^{14}$ Circadian variations have been found in tonic alertness, phasic alertness, and selective attention, which correlate with the rhythm of body temperature. In a constant routine protocol, lower performance occurred at 04:00-07:00. ${ }^{27}$ Similar results have been found in other studies. Tonic alertness, measured by reaction time, showed circadian variations that correlated with rhythm of body temperature in a forced desynchronization protocol. ${ }^{4}$ Selective attention also showed an association with melatonin circadian rhythm when studied on a constant routine protocol. ${ }^{40}$ In another study, circadian variations were found in several indices of sustained attention (general stability and short-term stability). ${ }^{41}$ The circadian variations in the components of attention may modulate changes in the performance of many tasks, such as reaction time, motor tasks, perception of time, and reading comprehension.

\section{Working memory}

Working memory is a neuropsychological process that provides temporary storage and manipulation of the information 
required for cognitive processing. ${ }^{42,43}$ Baddeley et al ${ }^{44}$ proposed a model of working memory that includes three storage components: phonologic, visuospatial, and an episodic buffer. The phonologic component stores verbal information, the visuospatial component stores visual information in a spatial map, and the episodic buffer component is a limited capacity temporary storage that integrates information from different sources into coherent episodes..$^{45}$ These components are coordinated by a central executive system. ${ }^{46}$ The left hemisphere is involved in phonological storage, whereas the right hemisphere is involved in a visuospatial storage component. ${ }^{47,48}$ On the other hand, the episodic buffer and central executive system are related to the frontal lobes. ${ }^{45,49}$ Ramírez et $\mathrm{al}^{8}$ used a constant routine protocol to assess the phonologic and visuospatial components of working memory. In this study, variations throughout the day were found in both storages of working memory. A decrease in the capacity to store phonologic and visuospatial information was found between 05:00 and 08:00. Also, these components of working memory correlate with the rhythm of body temperature. However, this is not an exact association, because the cycles of both storage components show a 1-3 hour delay in respect of the circadian rhythm of temperature. Another study found a decrease in the spatial component of working memory close to the acrophase of melatonin in a constant routine protocol..$^{50}$ The circadian variations in the phonologic storage may modulate the oscillations found in reading comprehension and verbal learning, whereas the circadian variations in visuospatial storage may explain the oscillations in drawing, construction, and arithmetic tasks. But circadian variations in the episodic buffer component of working memory have not been demonstrated.

\section{Executive functions}

Executive functions are the capacity to initiate, program, and control behavior. Therefore, they are critical for decision making, self-control, and problem solving. Executive functions include the following components: initiative, inhibition, flexibility, planning, prevision, self-monitoring, verification, and correction. ${ }^{51}$ These functions are integrated in the frontal lobe, as evidenced by the observations that lesions in this brain area cause impairment of one or several of these components. ${ }^{49,52}$ Initiative is the capacity to establish a goal, as well as to direct behavior toward the attainment of the set goal. Cognitive inhibition is the capacity to restrain behavior directed to secondary or irrelevant goals, ${ }^{53}$ whereas flexibility refers to the capacity to modify the response strategy according to changing environmental demands. ${ }^{54}$ Planning is the capacity to organize and program behavior according to preset goals. Prevision is the capacity to examine the possible consequences of events and actions that are planned. Selfmonitoring is the capacity of the person to observe and adjust their own actions to the requirements of the environment. Verification is the capacity to examine the results of their own actions. Finally, correction is the capacity to carry out actions that modify the results of their own actions, redirecting behavior toward the pre-set goal..$^{55,56}$

There are problems when assessing executive functions in laboratory conditions. Tests designed to measure executive functions require procedures that incorporate decision making, planning, and solving new problems..$^{57,58}$ Novelty in these tests is critical, because repeated practice may induce learning of the solution or of the strategy to solve the problem. To examine circadian rhythms in these functions, it is necessary to apply the test several times during the day. Therefore, the test ceases to be new. Some components of executive functions depend more on novelty, such as planning and prevision. On the other hand, to assess other components such as inhibition, flexibility, or selfmonitoring, it is feasible to use repeated tasks, such as Stroop tasks, go/no-go tasks, shifting criteria, and tracking tasks.

Harrison et al ${ }^{59}$ used a forced desynchronization protocol to study changes throughout the day in cognitive inhibition with a go/no-go task. Cognitive inhibition was worse when the body temperature was low. Other studies have found circadian variations in cognitive inhibition by means of a Stroop task in a constant routine protocol. ${ }^{60}$ Inhibition was lower at night and in the first hours of the morning (03:00-06:00). Similar circadian variations were also found with a computerized Stroop task, in a constant routine protocol. ${ }^{61}$ Circadian variations have been observed in cognitive flexibility, using a constant routine protocol, in two different Stroop tasks with shifting criteria. ${ }^{60,61}$ Flexibility was lower at night and in the first hours of the morning (03:00-06:00). Circadian variations have been also observed in self-monitoring, using a tracking task on a constant routine protocol. ${ }^{62}$ The lowest level of self-monitoring occurs at 05:00-09:00. The circadian variations in these components of executive functions (cognitive inhibition, flexibility, and self-monitoring) may modulate changes in the performance of all tasks requiring decision making or problem solving.

In summary, circadian rhythms in three basic neuropsychological processes (attention, working memory, and executive functions) have been demonstrated using constant routine or forced desynchronization protocols (Table 1). These processes are crucial to execute many tasks, so the performance of neuropsychological tests may be modulated by these rhythms. 
Table I Circadian rhythms in basic neuropsychological processes

\begin{tabular}{|c|c|c|c|c|}
\hline $\begin{array}{l}\text { Basic neuropsychological } \\
\text { process/components }\end{array}$ & Protocol & Task & $\begin{array}{l}\text { Results } \\
\text { Time of day } \\
\text { Highest/lowest level of cognitive } \\
\text { performance }\end{array}$ & Study \\
\hline $\begin{array}{l}\text { Attention } \\
\text { Tonic alertness }\end{array}$ & $\begin{array}{l}\text { Forced desynchronization } \\
\text { protocol }\end{array}$ & $\begin{array}{l}\text { Psychomotor vigilance task } \\
\text { (simple reaction time task) }\end{array}$ & $\begin{array}{l}\text { Day/night (rhythm of body temperature) } \\
6 / 12 \text { lapses } \\
300 \mathrm{~ms} / 450 \text { ms reaction time }\end{array}$ & Wright et $\mathrm{al}^{4}$ \\
\hline $\begin{array}{l}\text { Attention } \\
\text { Tonic alertness } \\
\text { Phasic alertness } \\
\text { Selective attention }\end{array}$ & $\begin{array}{l}\text { Constant routine } \\
\text { protocol }\end{array}$ & $\begin{array}{l}\text { Continuous performance } \\
\text { task }\end{array}$ & $\begin{array}{l}20: 00-23: 00 / 04: 00-07: 00 \\
\text { Tonic alertness } \\
90 \% / 70 \% \text { correct responses } \\
400 \mathrm{~ms} / 450 \mathrm{~ms} \text { reaction time } \\
\text { Phasic alertness } \\
80 \% / 60 \% \text { correct responses } \\
440 \mathrm{~ms} / 500 \mathrm{~ms} \text { reaction time } \\
\text { Selective attention } \\
75 \% / 55 \% \text { correct responses } \\
500 \mathrm{~ms} / 550 \mathrm{~ms} \text { reaction time }\end{array}$ & Valdez et $\mathrm{al}^{27}$ \\
\hline $\begin{array}{l}\text { Attention } \\
\text { Selective attention }\end{array}$ & $\begin{array}{l}\text { Constant routine } \\
\text { protocol }\end{array}$ & $\begin{array}{l}\text { Spatial-configuration } \\
\text { search task }\end{array}$ & $\begin{array}{l}\text { Day/night (rhythm of melatonin) } \\
\text { Figures } \\
700 \mathrm{~ms} / 850 \mathrm{~ms} \text { reaction time } \\
\text { Numbers } \\
1400 \mathrm{~ms} / \mathrm{l} 650 \mathrm{~ms} \text { reaction time }\end{array}$ & Horowitz et $\mathrm{al}^{40}$ \\
\hline $\begin{array}{l}\text { Attention } \\
\text { Sustained attention }\end{array}$ & $\begin{array}{l}\text { Constant routine } \\
\text { protocol }\end{array}$ & $\begin{array}{l}\text { Continuous performance } \\
\text { task }\end{array}$ & $\begin{array}{l}\text { 20:00-23:00/04:00-09:00 } \\
15 / 10 \text { hit runs } \\
\text { 3/10 error runs }\end{array}$ & Valdez et $\mathrm{al}^{41}$ \\
\hline $\begin{array}{l}\text { Working memory } \\
\text { Phonological storage } \\
\text { Visuospatial storage }\end{array}$ & $\begin{array}{l}\text { Constant routine } \\
\text { protocol }\end{array}$ & $\begin{array}{l}\text { Phonological } \\
\text { and visuospatial } \\
\text { working memory tasks }\end{array}$ & $\begin{array}{l}\text { I8:00-23:00/05:00-08:00 } \\
\text { Phonological storage } \\
90 \% / 75 \% \text { correct responses } \\
\text { Visuospatial storage } \\
85 \% / 75 \% \text { correct responses }\end{array}$ & Ramírez et $\mathrm{al}^{8}$ \\
\hline $\begin{array}{l}\text { Working memory } \\
\text { Phonological storage } \\
\text { Visuospatial storage }\end{array}$ & $\begin{array}{l}\text { Constant routine } \\
\text { protocol }\end{array}$ & $\begin{array}{l}\text { Verbal and spatial } \\
\mathrm{N} \text {-back tasks }\end{array}$ & $\begin{array}{l}\text { Day/night (rhythm of melatonin) } \\
\text { Phonological storage } \\
75 \% / 40 \% \text { correct responses } \\
\text { Visuospatial storage } \\
70 \% / 35 \% \text { correct responses }\end{array}$ & Groeger et al ${ }^{50}$ \\
\hline $\begin{array}{l}\text { Executive functions } \\
\text { Cognitive inhibition }\end{array}$ & $\begin{array}{l}\text { Forced desynchronization } \\
\text { protocol }\end{array}$ & Go/no-go task & $\begin{array}{l}\text { Day/night (rhythm of body temperature) } \\
20 \% / 30 \% \text { commission errors }\end{array}$ & Harrison et a $\left.\right|^{59}$ \\
\hline $\begin{array}{l}\text { Executive functions } \\
\text { Cognitive inhibition } \\
\text { Cognitive flexibility }\end{array}$ & $\begin{array}{l}\text { Constant routine } \\
\text { protocol }\end{array}$ & $\begin{array}{l}\text { Stroop task with } \\
\text { shifting criteria } \\
\text { ( } 48 \text { words) }\end{array}$ & $\begin{array}{l}\text { I8:00-23:00/03:00-06:00 } \\
\text { Inhibition } \\
43 \text { s/50 s reaction time } \\
\text { Flexibility } \\
50 \text { s/57 s reaction time }\end{array}$ & Ramírez et al ${ }^{60}$ \\
\hline $\begin{array}{l}\text { Executive functions } \\
\text { Cognitive inhibition } \\
\text { Cognitive flexibility }\end{array}$ & $\begin{array}{l}\text { Constant routine } \\
\text { protocol }\end{array}$ & $\begin{array}{l}\text { Computerized } \\
\text { Stroop-type task } \\
\text { with shifting criteria }\end{array}$ & $\begin{array}{l}\text { I8:00-23:00/03:00-06:00 } \\
\text { Inhibition } \\
85 \% / 70 \% \text { correct responses } \\
500 \mathrm{~ms} / 570 \mathrm{~ms} \text { reaction time } \\
\text { Flexibility } \\
65 \% / 45 \% \text { correct responses }\end{array}$ & García et $a^{61}$ \\
\hline $\begin{array}{l}\text { Executive functions } \\
\text { Self-monitoring }\end{array}$ & $\begin{array}{l}\text { Constant routine } \\
\text { protocol }\end{array}$ & Tracking task & $\begin{array}{l}\text { I8:00-23:00/05:00-09:00 } \\
4 / 14 \text { circles to adjust to changes in path }\end{array}$ & García et $a^{62}$ \\
\hline
\end{tabular}

Notes: This table includes only studies with constant routine or forced desynchronization protocol. In the forced desynchronization protocol, time of day is expressed as subjective day or night, according to the phase of the circadian rhythm of body temperature or melatonin.

\section{Time course of circadian rhythms in cognitive performance}

To understand the clinical implications of circadian rhythms in cognitive performance, an approximate time course of these rhythms is next described for an adult, healthy individual with an intermediate chronotype ${ }^{63}$ who sleeps from 23:00 to 07:00 (Figure 1). ${ }^{14,15,35}$ In this individual, the level of cognitive performance is low early in the morning (07:00-10:00), in part due to the fact that circadian rhythms reach their lowest point at dawn and in the first hours of the morning. Also, "sleep inertia" 


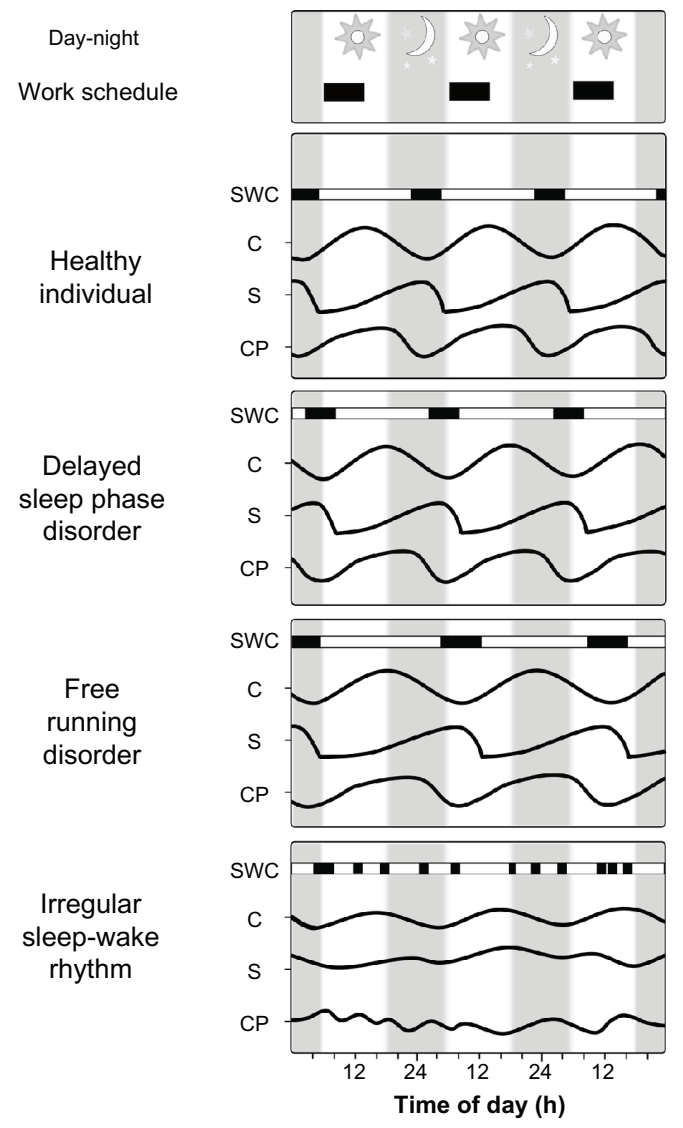

Figure I Time of day variations in the sleep-wake cycle (SWC), the circadian rhythm of body temperature (C), the sleepiness homeostatic factor (S), and (CP) cognitive performance in a healthy individual and patients with circadian sleep disorders.

occurs at this time of day, contributing to the low levels of cognitive execution. ${ }^{25}$ It is interesting to note that the morning shift, the most common work schedule in the world, generally begins at 07:00-09:00. Therefore, many people have to work for several hours when they are at their lowest level of cognitive performance (07:00-10:00). This may be the reason for the high levels of morning consumption of beverages containing central nervous system stimulants, such as coffee or tea. ${ }^{64-66}$ Performance improves toward noon (10:00-14:00), but there is a post-lunch dip at 14:00-16:00. ${ }^{26}$ Performance improves again in the afternoon, reaching its highest level in the evening (16:00-22:00). Finally, performance decreases at night (22:00-04:00) and reaches its lowest levels at dawn (04:00-07:00). ${ }^{15}$ It is important to keep in mind that this time course has been documented in healthy people, and that it is modulated by chronotype, ${ }^{67}$ age,${ }^{68}$ and sleep deprivation. ${ }^{69}$

\section{Implications for neuropsychological assessment}

Neuropsychological assessment consists of the application of a set of tests designed to examine the functional level of neuropsychological processes in patients with brain disorders. ${ }^{70}$ This assessment helps determine the processes that are affected and those that remain preserved. In children and adolescents with alterations in brain development, the assessment helps determine which processes are immature and which are intact. ${ }^{71}$ In this assessment, it is important to measure the maximum level that the patient may reach in each neuropsychological process in order to determine how affected that process is. In the clinical field, this assessment is very important because it helps to determine the functional consequences of the brain disorder besides being the base for the elaboration of a cognitive rehabilitation program. ${ }^{72}$

A great number of neuropsychological tests have been developed to assess brain functions through the measurement of the following dimensions of behavior: perception, attention, memory, learning, executive functions, language, and emotions. ${ }^{73}$ This assessment is applied in patients with very different brain disorders, such as traumatic head injury, stroke, dementia, developmental disorders, and psychiatric disorders.

Circadian rhythms in basic neuropsychological processes, as well as in the execution of a great number of tasks, affect performance in neuropsychological tests. However, they affect only the subtests that measure cognitive performance and do not have an effect on the subtests that measure overlearned knowledge, such as the vocabulary test, ${ }^{74}$ or on tests that measure general dimensions of behavior, such as intelligence and personality, which are deemed stable over time. ${ }^{71}$ Nonetheless, in the clinical field, circadian rhythms are neglected when a neuropsychological assessment is made. Also, they are neglected if the patient exhibits alterations in circadian rhythms, which may also affect performance in these tests.

As mentioned previously, the time course of circadian rhythms in cognitive performance is based on recordings of healthy people, because the studies that have documented circadian variations in cognitive execution in patients are scarce. According to this time course, performance in neuropsychological tests would be expected to be low before 10:00, at 14:00-16:00, and after 22:00. Performance would be relatively satisfactory at 10:00-14:00 and 16:00-22:00. In general, these intervals coincide with the office hours when neuropsychological tests are applied. However, the intervals of best and worst execution may vary significantly in patients with brain disorders, due to the following factors: chronotype, age, alterations of the circadian rhythm, sleep deprivation, type of disorder, and the medication the patient is on. 


\section{Chronotype}

There are individual differences in the sleep-wake cycle. Some individuals wake up early and are more active in the morning (morning type), whereas others wake up late and are more active in the evening (evening type). Horne and Östberg ${ }^{63}$ developed a questionnaire that helps determine the chronotype of individuals, based on their preferences for carrying out different activities in the course of the day. According to the results of the questionnaire, individuals can be classified as morning type, evening type, or intermediate type. Morning-type individuals phase advance the sleep-wake cycle and the rhythm in body temperature, whereas evening-type individuals phase delay these rhythms. ${ }^{75,76}$ Cognitive performance varies during the day depending on chronotype. Morning-type individuals show best execution in the morning, with worst execution in the afternoon, whereas evening-type individuals show an inverse pattern. ${ }^{67}$

\section{Age}

As people grow old, changes occur in the phase of the circadian rhythm that affects the time course of cognitive performance. Adolescents show a phase delay of their sleep-wake cycle. ${ }^{77-80}$ Therefore, their cognitive performance is lower during the morning, especially in those that are evening-type individuals. ${ }^{74}$ Elderly people show an increase in reaction time ${ }^{81}$ and a reduction in several cognitive functions, such as attention, ${ }^{82}$ memory, ${ }^{83}$ and executive functions ${ }^{84,85}$ In addition, they tend to be morning-type individuals $;{ }^{86}$ they show awakenings in the night, greater frequency and duration of naps during the day, and an increase in daytime sleepiness, ${ }^{87}$ especially in the afternoon. ${ }^{88}$ At this age, an increase in reaction time and a lower performance in neuropsychological tests have been found during the afternoon. ${ }^{68}$ Also, elderly people show lower amplitude in circadian rhythms of cognitive performance. ${ }^{89}$

\section{Circadian rhythm sleep disorders}

Circadian rhythm sleep disorders refer to a persistent or recurrent pattern in the sleep-wake cycle, with the following characteristics: changes in circadian rhythm, discrepancy between circadian rhythm and external factors that promote the phase or the duration of sleep, difficulties sleeping at night and sleepiness during the daytime, as well as changes in work or social activities. ${ }^{90,91}$ Circadian rhythm sleep disorders that have more effects on the time course of cognitive performance are delayed sleep phase disorder, free-running disorder, and irregular sleep-wake rhythm (Figure 1). ${ }^{92}$
Delayed sleep phase disorder is a chronic disorder that usually begins in childhood and prevails for periods from 6 months to the person's lifetime. Patients with this syndrome are extreme evening-type individuals who have problems in advancing their sleep-wake cycle. ${ }^{93,94}$ They go to bed at dawn (around 05:00) and wake up at noon or later. During free days (holidays, weekends), their sleep is normal in quantity and quality, but it is delayed in respect of their calendar of social activities. Their sleep time is drastically reduced when they must attend school or work a morning shift. This partial sleep deprivation becomes a chronic problem that brings about sleepiness and tiredness during the day.

Free-running disorder (non-24-hour sleep-wake syndrome) is characterized by a circadian rhythm with a period close to 25 hours, despite the patient living in a natural environment with a 24 -hour cycle. ${ }^{95}$ This may be interpreted as a failure in the circadian clock to adjust to zeitgebers. ${ }^{96}$ Patients with this disorder sleep later each day, getting in and out of phase successively in respect of the day and night, so that for some periods they sleep at night, but after several days they sleep during the daytime. This disorder is frequent in the blind, although sighted people have also been found with this syndrome.

Patients with an irregular sleep-wake rhythm disorder sleep for short periods distributed during the 24 hours of the day. They have four or five bouts of sleep, totaling 8 hours per day. It may be due to damage of the circadian clock. It commonly appears in elderly people, especially when they do not maintain programmed activities in fixed schedules or they are not exposed to sunlight..$^{93,97}$

\section{Sleep deprivation}

Sleep deprivation affects cognitive performance. Greater levels of sleep deprivation produce more decay in performance throughout the day. ${ }^{69,98}$ Sleep deprivation interacts with circadian rhythms, producing lower cognitive performance in the morning and at night and a post-lunch dip. As a consequence, sleep deprivation may also affect performance in neuropsychological tests; however, this factor is also neglected when a neuropsychological assessment is made. ${ }^{99}$

\section{Brain disorders}

\section{Traumatic head injury}

Approximately $30 \%-70 \%$ of patients with traumatic head injury suffer sleep disorders, especially insomnia ${ }^{100-102}$ and daytime sleepiness. ${ }^{103-106}$ These disorders are found particularly during the first months after the accident, although they may persist chronically. Also, in polysomnographic 
recordings, greater sleep latency has been found in these patients, as well as lower sleep efficiency. ${ }^{103}$ Some of these patients suffer a circadian rhythm sleep disorder. ${ }^{107,108}$ In patients with traumatic head injury, free-running disorders and delayed sleep phase disorders have been documented. ${ }^{109-111}$ On the other hand, these patients show alterations in a great number of neuropsychological processes. ${ }^{112-114}$ Orff et al ${ }^{115}$ suggest the possibility that the circadian rhythm sleep disorders are responsible for the low cognitive performance found in patients with mild traumatic head injury. Therefore, it is probable that these patients' performance in neuropsychological tests varies at different hours of the day. It is necessary to carry out specific studies to document circadian variations in the neuropsychological assessment of these patients.

\section{Stroke}

Patients with stroke show an increase in sleep duration and daytime sleepiness. ${ }^{116}$ These patients also report fatigue and attention and memory problems during the day. ${ }^{117}$ In addition, a disruption of the circadian rhythm was found in blood pressure in patients with stroke at their hospitalization time, because their blood pressure did not fall during the night. ${ }^{118}$ Performance in neuropsychological tests was consistent with the chronotype of stroke and traumatic brain injury inpatients in a rehabilitation center. Morning-type patients showed best performance in the morning, whereas evening-type patients showed best performance in the afternoon. ${ }^{119}$

\section{Dementia}

Patients with Alzheimer dementia show a greater incidence of insomnia and daytime sleepiness, as well as frequent awakenings during the night and lower sleep efficiency. ${ }^{120}$ Also, their symptoms worsen in the afternoon and first hours of the evening ("sundowning"). During these hours they tend to show agitation, confusion, and hallucinations. ${ }^{121,122}$ Cognitive performance is progressively affected in patients with dementia, and the speed with which cognition declines has been associated with the presence of sundowning. ${ }^{123}$ The possibility that this phenomenon is due to changes in the circadian rhythm has been proposed, ${ }^{124}$ as these patients show a phase delay in the circadian rhythm of body temperature and in motor activity. ${ }^{125}$ A delayed sleep-wake disorder has also been found in patients with fronto-temporal dementia. ${ }^{126}$

\section{Schizophrenia}

Patients with schizophrenia have trouble initiating and maintaining sleep. It has been found that these patients show circadian rhythm sleep disorders, some show a delayed sleep phase disorder, and others show an irregular sleep-wake rhythm disorder. Also, cognitive performance is worse in patients with schizophrenia who show alterations in the sleep-wake cycle. ${ }^{127}$ It has been found that patients with schizophrenia show changes with time of day in the performance of neuropsychological tests, with best execution in the afternoon. ${ }^{128}$

\section{Depression}

Patients with depression suffer insomnia, have trouble initiating sleep, show frequent awakenings during the night, and wake up very early in the morning. ${ }^{129}$ Their emotional state is worst during the morning ${ }^{130}$ and improves toward the end of the day. ${ }^{131}$ Also, these patients' performance in neuropsychological tests is worst in the morning and best in the afternoon. ${ }^{132}$

\section{Obsessive compulsive disorder}

Patients with obsessive compulsive disorder show a reduction in the amplitude of the melatonin circadian rhythm, ${ }^{133}$ and some of them show a delayed sleep phase disorder. ${ }^{134,135}$ A deficit in executive functions has been documented in obsessive compulsive disorder patients, ${ }^{136-139}$ but there are no studies documenting time of day changes in cognitive performance.

\section{Attention deficit hyperactivity disorder}

It has been found that children with attention deficit hyperactivity disorder (ADHD) sleep less during the night. ${ }^{140}$ An increase in sleepiness during the day has been found, especially in the morning, as measured with the multiple sleep latencies test. ${ }^{141}$ Also, children with ADHD show low sleep efficiency and low levels of performance in cognitive tasks. ${ }^{142}$ Some patients with ADHD show a delayed sleep phase disorder. ${ }^{143,144}$ In another study, a phase delay in the circadian rhythm of cortisol of adults with ADHD was found. ${ }^{145}$ Other studies have observed a delay in the circadian rhythm of melatonin, as well as in the sleep-wake cycle, especially in ADHD patients who reported sleep onset insomnia. ${ }^{146,147}$ Performance in neuropsychological tests of children with ADHD is lower in the afternoon, ${ }^{148}$ which coincides with the time of the day when they show an increase in level of hyperactivity. ${ }^{149}$

\section{Medication}

Certain drugs modulate the time course of rhythms in cognitive performance. Patients with brain disorders often take 
medication that affects the central nervous system, such as antiepileptic drugs, stimulants, anxiolytic or hypnotic drugs, antidepressants, or antipsychotic medication. All of these drugs may affect cognitive performance, circadian rhythms, or sleep. For example, haloperidol suppresses circadian rhythms of the sleep-wake cycle and of cognitive performance. ${ }^{150-152}$

\section{Conclusion}

According to data reviewed in this paper, performance in neuropsychological tests is affected by circadian rhythms in cognitive processes. During the day, healthy people show acceptable levels of cognitive performance from 10:00 to 14:00 and from 16:00 to 22:00, which coincides with the office hours when the neuropsychological assessment is normally scheduled. However, it is important to consider that the time course of cognitive performance in patients with brain disorders may be affected by other factors, such as chronotype, age, circadian rhythm disorders, sleep deprivation, type of disorder, and medication. Patients with brain disorders suffer deficits in many neuropsychological processes, and they may be more sensitive to time of day effects, to sleep deprivation, and to medication effects.

It is necessary to carry out more research on circadian rhythms in cognitive performance of patients with brain disorders, the factors that affect these rhythms, and the consequences of these rhythms on the neuropsychological assessment. In the clinical field, it is important to take into account the circadian rhythms in cognitive performance of each patient when scheduling the neuropsychological assessment sessions.

Recommendations for scheduling the neuropsychological assessment sessions, according to the circadian rhythms in cognitive performance, are as follows:

1. Assess the patient's sleep-wake cycle. Schedule the neuropsychological assessment at least 3 hours after his/her regular wake-up time.

2. Assess the patient's chronotype. Schedule testing sessions in the morning for morning-type patients and in the afternoon for evening-type patients.

3. Evaluate the quality of sleep the night before the testing session. Reschedule the session if the patient did not sleep well.

4. Document the patient's medication list. When possible, schedule testing sessions in medication-free days.

\section{Disclosure}

The authors report no conflicts of interest in this work.

\section{References}

1. Moore-Ede MC, Sulzman FM, Fuller CA. The Clocks That Time Us: Physiology of the Circadian Timing System. Cambridge, MS: Harvard University Press; 1982.

2. Lotze M, Wittmann M, von Steinbüchel N, Pöppel E, Roenneberg T. Daily rhythm of temporal resolution in the auditory system. Cortex. 1999;35(1):89-100.

3. Edwards B, Waterhouse J, Reilly T. The effects of circadian rhythmicity and time-awake on a simple motor task. Chronobiol Int. 2007;24(6): 1109-1124.

4. Wright KP Jr, Hull JT, Czeisler CA. Relationship between alertness, performance, and body temperature in humans. Am J Physiol Regul Integr Comp Physiol. 2002;283(6):R1370-R1377.

5. Campbell SS, Murphy PJ, Boothroyd CE. Long-term time estimation is influenced by circadian phase. Physiol Behav. 2001;72(4): 589-593.

6. Kuriyama K, Uchiyama M, Suzuki H, et al. Circadian fluctuation of time perception in healthy human subjects. Neurosci Res. 2003;46(1): 23-31.

7. Folkard S, Monk TH. Circadian rhythms in human memory. $\mathrm{Br} J$ Psychol. 1980;71(2):295-307.

8. Ramírez C, Talamantes J, García A, Morales M, Valdez P, MennaBarreto L. Circadian rhythms in phonological and visuospatial storage components of working memory. Biol Rhythm Res. 2006;37(5): 433-441.

9. Monk TH, Carrier J. Speed of mental processing in the middle of the night. Sleep. 1997;20(6):399-401.

10. Blake MJF. Time of day effects on performance in a range of task. Psychon Sci. 1967;9(6):349-350.

11. Lenné MG, Triggs TJ, Redman JR. Time of day variations in driving performance. Accid Anal Prev. 1997;29(4):431-437.

12. Colquhoun WP. Circadian variations in mental efficiency. In: Colquhoun WP, editor. Biological Rhythms and Human Performance. New York, NY: Academic Press; 1971:39-107.

13. Lavie P. The search for cycles in mental performance from Lombard to Kleitman. Chronobiologia. 1980;7(2):247-256.

14. Carrier J, Monk TH. Circadian rhythms of performance: new trends. Chronobiol Int. 2000;17(6):719-732.

15. Wright KP, Lowry CA, LeBourgeois MK. Circadian and wakefulnesssleep modulation of cognition in humans. Front Mol Neurosci. 2012;5:50. doi: 10.3389/fnmol.2012.00050.

16. Duffy JF, Dijk DJ. Getting through to circadian oscillators: why use constant routines? J Biol Rhythms. 2002;17(1):4-13.

17. Czeisler CA, Duffy JF, Shanahan TL, et al. Stability, precision, and near-24-hour period of the human circadian pacemaker. Science. 1999;284(5423):2177-2181.

18. Cajochen C, Khalsa SBS, Wyatt JK, Czeisler CA, Dijk DJ. EEG and ocular correlates of circadian melatonin phase and human performance decrements during sleep loss. Am J Physiol. 1999;277(3 Pt 2): R640-R649.

19. Hanneman SK. Measuring circadian temperature rhythm. Biol Res Nurs. 2001;2(4):236-248.

20. Blatter K, Cajochen C. Circadian rhythms in cognitive performance: methodological constraints, protocols, theoretical underpinnings. Physiol Behav. 2007;90(2-3):196-208.

21. Kleitman N. Sleep and Wakefulness. 2nd ed. Chicago, IL: University of Chicago Press; 1963.

22. Kraemer S, Danker-Hopfe H, Dorn H, Schmidt A, Ehlert I, Herrmann WM. Time-of-day variations of indicators of attention performance, physiologic parameters, and self-assessment of sleepiness. Biol Psychiatry. 2000;48(11):1069-1080.

23. Borbély AA. A two process model of sleep regulation. Human Neurobiol. 1982;1(3):195-204.

24. Kripke DF. Ultradian rhythms in sleep and wakefulness. In: Weitzman ED, editor. Advances in Sleep Research. New York, NY: Spectrum Publications; 1974:305-325.

25. Tassi P, Muzet A. Sleep inertia. Sleep Med Rev. 2000;4(4):341-353. 
26. Babkoff H, Caspy T, Mikulincer M. Subjective sleepiness ratings: the effects of sleep deprivation, circadian rhythmicity and cognitive performance. Sleep. 1991;14(6):534-539.

27. Valdez P, Ramírez C, García A, Talamantes J, Armijo P, Borrani J. Circadian rhythms in components of attention. Biol Rhythm Res. 2005; 36(1/2):57-65.

28. Tassi P, Pellerin N, Moessinger M, Eschenlauer R, Muzet A. Variation of visual detection over the 24-hour period in humans. Chronobiol Int. 2000;17(6):795-805.

29. Jasper I, Häußler A, Baur B, Marquardt C, Hermsdörfer J. Circadian variations in the kinematics of handwriting and grip strength. Chronobiol Int. 2009;26(3):576-594.

30. Blatter K, Graw P, Münch M, Knoblauch V, Wirz-Justice A, Cajochen C. Gender and age differences in psychomotor vigilance performance under differential sleep pressure conditions. Behav Brain Res. 2006;168(2):312-317.

31. Bratzke D, Rolke B, Steinborn MB, Ulrich R. The effect of $40 \mathrm{~h}$ constant wakefulness on task-switching efficiency. J Sleep Res. 2009;18(2): $167-172$.

32. Monk TH, Buysse DJ, Reynolds CF, Kupfer DJ. Endogenous circadian performance rhythms-relationship to temperature, cortisol, melatonin, mood and alertness. In: Touitou Y, editor. Biological Clocks, Mechanisms and Applications. New York, NY: Elsevier Science BV; 1998:557-562.

33. Gillberg M, Kecklund G, Åkerstedt T. Sleepiness and performance of professional drivers in a truck simulator comparisons between day and night driving. J Sleep Res. 1996;5(1):12-15.

34. Schmidt C, Collette F, Cajochen C, Peigneux P. A time to think: circadian rhythms in human cognition. Cogn Neuropsychol. 2007;24(7): 755-789.

35. Valdez P, Reilly T, Waterhouse J. Rhythms of mental performance. Mind Brain Educ. 2008;2(1):7-16.

36. Cohen RA, O'Donnell BF. Models and mechanisms of attention. In: Cohen RA, Sparling-Cohen YA, O'Donnell BF, editors. The Neuropsychology of Attention. New York, NY: Plenum Press; 1993:177-186.

37. Posner MI, Rafal RD. Cognitive theories of attention and the rehabilitation of attentional deficits. In: Meier MJ, Benton AL, Diller L, editors. Neuropsychological Rehabilitation. New York, NY: Guilford Press; 1987:182-201.

38. Berger A, Posner MI. Pathologies of brain attentional networks. Neurosci Biobehav Rev. 2000;24(1):3-5.

39. Sarter M, Givens B, Bruno JP. The cognitive neuroscience of sustained attention: where top-down meets bottom-up. Brain Res Rev. 2001; 35(2):146-160.

40. Horowitz TS, Cade BE, Wolfe JM, Czeisler CA. Searching night and day: a dissociation of effects of circadian phase and time awake on visual selective attention and vigilance. Psychol Sci. 2003;14(6):549-557.

41. Valdez P, Ramírez C, García A, Talamantes J, Cortez J. Circadian and homeostatic variation in sustained attention. Chronobiol Int. 2010;27(2):393-416.

42. Logie R, Baddeley A, Mané A, Donchin E, Sheptak R. Working memory in the acquisition of complex cognitive skills. Acta Psychol (Amst). 1989;71:53-87.

43. Logie RH, Zucco GM, Baddeley AD. Interference with visual shortterm memory. Acta Psychol (Amst). 1990;75(1):55-74.

44. Baddeley AD, Hatter JE, Scott D, Snashall A. Memory and time of day. Q J Exp Psychol. 1970;22(4):605-609.

45. Baddeley A. The episodic buffer: a new component of working memory? Trends Cogn Sci. 2000;4(11):417-423.

46. Baddeley A. The fractionation of working memory. Proc Natl Acad Sci US A. 1996;93(24):13468-13472.

47. Petrides M, Milner B. Deficits on subject-ordered tasks after frontaland temporal-lobe lesions in man. Neuropsychologia. 1982;20(3): 249-262.

48. Reuter-Lorenz PA, Jonides J, Smith EE, et al. Age differences in the frontal lateralization of verbal and spatial working memory revealed by PET. J Cogn Neurosci. 2000;12(1):174-187.
49. Luria AR. Las Funciones Corticales Superiores del Hombre. México: Fontamara; 1986.

50. Groeger JA, Viola AU, Lo JCY, von Schantz M, Archer SN, Dijk DJ. Early morning executive functioning during sleep deprivation is compromised by a PERIOD3 polymorphism. Sleep. 2008;31(8):1159-1167.

51. Stuss DT. Functions of the frontal lobes: relation to executive functions. J Int Neuropsychol Soc. 2011;17(5):759-765.

52. Heilman KM, Valenstein E. Clinical neuropsychology. New York, NY: Oxford University Press; 2003.

53. Nigg JT. On inhibition/disinhibition in developmental psychopathology: views from cognitive and personality psychology and a working inhibition taxonomy. Psychol Bull. 2000;126(2):220-246.

54. Miller EK, Cohen JD. An integrative theory of prefrontal cortex function. Annu Rev Neurosci. 2001;24:167-202.

55. Godefroy O. Frontal syndrome and disorders of executive functions. J Neurol. 2003;250(1):1-6.

56. Stuss DT, Levine B. Adult clinical neuropsychology: lessons from studies of the frontal lobes. Annu Rev Psychol. 2002;53:401-433.

57. Alexander M, Stuss DT. Frontal injury: impairments of fundamental processes lead to functional consequences. J Int Neuropsychol Soc. 2006;12(2):192-193.

58. Jones K, Harrison Y. Frontal lobe function, sleep loss and fragmented sleep. Sleep Med Rev. 2001;5(6):463-475.

59. Harrison Y, Jones K, Waterhouse J. The influence of time awake and circadian rhythm upon performance on a frontal lobe task. Neuropsychologia. 2007;45(8):1966-1972.

60. Ramírez C, García A, Valdez P. Identification of circadian rhythms in cognitive inhibition and flexibility using a Stroop task. Sleep Biol Rhythms. 2012;10(2):136-144.

61. García A, Ramírez C, Martínez B, Valdez P. Circadian rhythms in two components of executive functions: cognitive inhibition and flexibility. Biol Rhythm Res. 2012;43(1):49-63.

62. García A, Ramírez C, Valdez P. Circadian variations in the capacity to adjust behavior to environmental changes. Sleep Sci. 2010;3(1):56-60.

63. Horne JA, Östberg O. A self-assessment questionnaire to determine morningness-eveningness in human circadian rhythms. Int $J$ Chronobiol. 1976;4(2):97-110.

64. Reyner LA, Horne JA. Early morning driver sleepiness: effectiveness of $200 \mathrm{mg}$ caffeine. Psychophysiology. 2000;37(2):251-256.

65. Van Dongen HP, Price NJ, Mullington JM, Szuba MP, Kapoor SC, Dinges DF. Caffeine eliminates psychomotor vigilance deficits from sleep inertia. Sleep. 2001;24(7):813-819.

66. Carrier J, Paquet J, Fernandez-Bolanos M, et al. Effects of caffeine on daytime recovery sleep: a double challenge to the sleep-wake cycle in aging. Sleep Med. 2009;10(9):1016-1024.

67. May CP. Synchrony effects in cognition: the costs and a benefit. Psychon Bull Rev. 1999;6(1):142-147.

68. May CP, Hasher L, Stoltzfus ER. Optimal time of day and the magnitude of age differences in memory. Psychol Sci. 1993;4(5):326-330.

69. Taub JM, Berger RJ. Performance and mood following variations in the length and timing of sleep. Psychophysiology. 1973;10(6):559-570.

70. Lezak MD, Howieson DB, Loring DW. Neuropsychological Assessment. 4th ed. New York, NY: Oxford University Press; 2004.

71. Baron I. Neuropsychological Evaluation of the Child. Oxford, UK: Oxford University Press; 2004.

72. Sohlberg M, Mateer C. Cognitive rehabilitation: an integrative neuropsychological approach. New York, NY: Guilford Press; 2001.

73. Strauss E, Sherman EMS, Spreen O. A Compendium of Neuropsychological Tests: Administration, Norms, and Commentary. 3rd ed. New York, NY: Oxford University Press; 2006.

74. Goldstein D, Hahn CS, Hasher L, Wiprzycka UJ, Zelazo PD. Time of day, intellectual performance, and behavioral problems in morning versus evening type adolescents: is there a synchrony effect? Pers Individ Dif. 2007;42(3):431-440.

75. Kerkhof GA, Van Dongen HPA. Morning-type and evening-type individuals differ in the phase position of their endogenous circadian oscillator. Neurosci Lett. 1996;218(3):153-156. 
76. Benedito-Silva AA, Menna-Barreto L, Marques N, Tenreiro S. A selfassessment questionnaire for the determination of morningnesseveningness types in Brazil. Prog Clin Biol Res. 1990;341B:89-98.

77. Valdez P, Ramírez C, García A. Delaying and extending sleep during weekends: sleep recovery or circadian effect? Chronobiol Int. 1996; 13(3):191-198.

78. Carskadon MA, Vieira C, Acebo C. Association between puberty and delayed phase preference. Sleep. 1993;16(3):258-262.

79. Andrade MM, Benedito-Silva AA, Domenice S, Arnhold IJ, MennaBarreto L. Sleep characteristics of adolescents: a longitudinal study. J Adolesc Health. 1993;14(5):401-406.

80. Crowley SJ, Acebo C, Carskadon MA. Sleep, circadian rhythms, and delayed phase in adolescence. Sleep Med. 2007;8(6):602-612.

81. Der G, Deary IJ. Age and sex differences in reaction time in adulthood: results from the United Kingdom health and lifestyle survey. Psychol Aging. 2006;21(1):62-73.

82. Madden DJ. Aging and visual attention. Curr Dir Psychol Sci. 2007; 16(2):70-74

83. Rowe G, Hasher L, Turcotte J. Age differences in visuospatial working memory. Psychol Aging. 2008;23(1):79-84.

84. Chao LL, Knight RT. Prefrontal deficits in attention and inhibitory control with aging. Cereb Cortex. 1997;7(1):63-69.

85. Lustig C, Hasher L, Zacks R. Inhibitory deficit theory: recent developments in a "new view". In: Gorfein DS, MacLeod CM, editors. Inhibition in Cognition. Washington, DC: American Psychological Association; 2007:145-162.

86. Mecacci L, Zani A, Rocchetti G, Lucioli R. The relationships between morningness-eveningness, ageing and personality. Pers Individ Dif. 1986;7(6):911-913.

87. Carskadon MA, Brown ED, Dement WC. Sleep fragmentation in the elderly: relationship to daytime sleep tendency. Neurobiol Aging. 1982; 3(4):321-327.

88. Fragoso CA, Gill TM. Sleep complaints in community-living older persons: a multifactorial geriatric syndrome. J Am Geriatr Soc. 2007; 55(11):1853-1866.

89. Sagaspe P, Taillard J, Amiéva H, et al. Influence of age, circadian and homeostatic processes on inhibitory motor control: a go/nogo task study. PLoS One. 2012;7(6):e39410. doi:39410.31371/journal. pone.0039410.

90. Dagan Y, Eisenstein M. Circadian rhythm sleep disorders: toward a more precise definition and diagnosis. Chronobiol Int. 1999;16(2): 213-222.

91. Kolla B, Auger R, Morgenthaler T. Circadian rhythm sleep disorders. ChronoPhysiology and Therapy. 2012;2(1):19-34.

92. Sack RL, Auckley D, Auger RR, et al. Circadian rhythm sleep disorders. Part II, Advanced sleep phase disorder, delayed sleep phase disorder, free-running disorder, and irregular sleep-wake rhythm. An American Academy of Sleep Medicine review. Sleep. 2007;30(11): 1484-1501.

93. Barion A, Zee PC. A clinical approach to circadian rhythm sleep disorders. Sleep Med. 2007;8(6):566-577.

94. Czeisler CA, Allan JS. Pathologies of the sleep-wake cycle schedule. In: Williams RL, Karacan I, Moore CA, editors. 2nd ed. Sleep Disorders: Diagnosis and Treatment. New York, NY: John Wiley and Sons; 1988.

95. Miles LE, Raynal DM, Wilson MA. Blind man living in normal society has circadian rhythms of 24.9 hours. Science. 1977;198(4315): 421-423.

96. Klein T, Martens H, Dijk DJ, Kronauer RE, Seely EW, Czeisler CA. Circadian sleep regulation in the absence of light perception: chronic non-24-hour circadian rhythm sleep disorder in a blind man with a regular 24-hour sleep-wake schedule. Sleep. 1993;16(4):333-343.

97. Zee PC, Vitiello MV. Circadian rhythm sleep disorder: irregular sleep wake rhythm type. Sleep Med Clin. 2009;4(2):213-218.

98. Kim DJ, Lee HP, Kim MS, et al. The effect of total sleep deprivation on cognitive functions in normal adult male subjects. Int J Neurosci. 2001;109(1-2):127-137.
99. Waters F, Bucks RS. Neuropsychological effects of sleep loss: implication for neuropsychologists. J Int Neuropsychol Soc. 2011;4:1-16.

100. Fichtenberg NL, Millis SR, Mann NR, Zafonte RD, Millard AE. Factors associated with insomnia among post-acute traumatic brain injury survivors. Brain Inj. 2000;14(7):659-667.

101. Ouellet MC, Savard J, Morin CM. Insomnia following traumatic brain injury: a review. Neurorehabil Neural Repair. 2004;18(4):187-198.

102. Beetar JT, Guilmette TJ, Sparadeo FR. Sleep and pain complaints in symptomatic traumatic brain injury and neurologic populations. Arch Phys Med Rehabil. 1996;77(12):1298-1302.

103. Parcell DL, Ponsford JL, Rajaratnam SM, Redman JR. Self-reported changes to nighttime sleep after traumatic brain injury. Arch Phys Med Rehabil. 2006;87(2):278-285.

104. Cohen M, Oksenberg A, Snir D, Stern MJ, Groswasser Z. Temporally related changes of sleep complaints in traumatic brain injured patients. J Neurol Neurosurg Psychiatry. 1992;55(4):313-315.

105. Schreiber S, Barkai G, Gur-Hartman T, et al. Long-lasting sleep patterns of adult patients with minor traumatic brain injury (mTBI) and non-mTBI subjects. Sleep Med. 2008;9(5):481-487.

106. Watson NF, Dikmen S, Machamer J, Doherty M, Temkin N. Hypersomnia following traumatic brain injury. J Clin Sleep Med. 2007;3(4):363-368.

107. Patten SB, Lauderdale WM. Delayed sleep phase disorder after traumatic brain injury. J Am Acad Child Adolesc Psychiatry. 1992; 31(1):100-102.

108. Castriotta RJ, Murthy JN. Sleep disorders in patients with traumatic brain injury: a review. CNS Drugs. 2011;25(3):175-185.

109. Boivin DB, Caliyurt O, James FO, Chalk C. Association between delayed sleep phase and hypernyctohemeral syndromes: a case study. Sleep. 2004;27(3):417-421.

110. Quinto C, Gellido C, Chokroverty S, Masdeu J. Posttraumatic delayed sleep phase syndrome. Neurology. 2000;54(1):250-252.

111. Ayalon L, Borodkin K, Dishon L, Kanety H, Dagan Y. Circadian rhythm sleep disorders following mild traumatic brain injury. Neurology. 2007;68(14):1136-1140.

112. Mahmood O, Rapport LJ, Hanks RA, Fichtenberg NL. Neuropsychological performance and sleep disturbance following traumatic brain injury. J Head Trauma Rehabil. 2004;19(5):378-390.

113. Lundin A, de Boussard C, Edman G, Borg J. Symptoms and disability until 3 months after mild TBI. Brain Inj. 2006;20(8):799-806.

114. Bohnen N, Jolles J, Twijnstra A. Neuropsychological deficits in patients with persistent symptoms six months after mild head injury. Neurosurgery. 1992;30(5):692-696.

115. Orff HJ, Ayalon L, Drummond SPA. Traumatic brain injury and sleep disturbance: a review of current research. J Head Trauma Rehabil. 2009;24(3):155-165

116. Vock J, Achermann P, Bischof M, et al. Evolution of sleep and sleep EEG after hemispheric stroke. J Sleep Res. 2002;11(4):331-338.

117. Hermann DM, Siccoli M, Bassetti CL. Sleep-wake disorders and stroke. Schweiz Arch Neurol Psychiatr. 2003;154:369-373.

118. Jain S, Namboodri KK, Kumari S, Prabhakar S. Loss of circadian rhythm of blood pressure following acute stroke. BMC Neurol. 2004;4:1. doi:10.1186/1471-2377-1184-1181.

119. Paradee CV, Rapport LJ, Hanks RA, Levy JA. Circadian preference and cognitive functioning among rehabilitation inpatients. Clin Neuropsychol. 2005;19(1):55-72.

120. Weldemichael DA, Grossberg GT. Circadian rhythm disturbances in patients with Alzheimer's disease: a review. Int $J$ Alzheimers Dis. 2010;2010. doi:10.4061/2010/716453.

121. O'Leary PA, Haley WE, Paul PB. Behavioral assessment in Alzheimer's disease: use of a 24-hr log. Psychol Aging. 1993;8(2):139-143.

122. Martin J, Marler M, Shochat T, Ancoli-Israel S. Circadian rhythms of agitation in institutionalized patients with Alzheimer's disease. Chronobiol Int. 2000;17(3):405-418.

123. Bliwise DL, Yesavageb JA, Tinklenberg JR. Sundowning and rate of decline in mental function in Alzheimer's disease. Dementia. 1992; 3(5-6):335-341. 
124. Bachman D, Rabins P. "Sundowning" and other temporally associated agitation states in dementia patients. Annu Rev Med. 2006;57: 499-511.

125. Satlin A, Volicer L, Stopa EG, Harper D. Circadian locomotor activity and core-body temperature rhythms in Alzheimer's disease. Neurobiol Aging. 1995;16(5):765-771.

126. Anderson KN, Hatfield C, Kipps C, Hastings M, Hodges JR. Disrupted sleep and circadian patterns in frontotemporal dementia. Eur J Neurol. 2009;16(3):317-323.

127. Bromundt V, Koster M, Georgiev-Kill A, et al. Sleep-wake cycles and cognitive functioning in schizophrenia. Br J Psychiatry. 2011;198(4): 269-276.

128. D'Reaux RA, Neumann CS, Rhymer KN. Time of day of testing and neuropsychological performance of schizophrenic patients and healthy controls. Schizophr Res. 2000;45(1-2):157-167.

129. Germain A, Kupfer DJ. Circadian rhythm disturbances in depression. Hum Psychopharmacol. 2008;23(7):571-585.

130. Gordijn MC, Beersma DG, Bouhuys AL, Reinink E, Van den Hoofdakker RH. A longitudinal study of diurnal mood variation in depression; characteristics and significance. J Affect Disord. 1994; 31(4):261-273.

131. Boivin DB. Influence of sleep-wake and circadian rhythm disturbances in psychiatric disorders. J Psychiatry Neurosci. 2000;25(5): 446-458.

132. Moffoot AP, O'Carroll RE, Bennie J, et al. Diurnal variation of mood and neuropsychological function in major depression with melancholia. J Affect Disord. 1994;32(4):257-269.

133. Monteleone P, Catapano F, Del Buono G, Maj M. Circadian rhythms of melatonin, cortisol and prolactin in patients with obsessive-compulsive disorder. Acta Psychiatr Scand. 1994;89(6):411-415.

134. Lange KW, Lange KM, Hauser J, Tucha L, Tucha O. Circadian rhythms in obsessive-compulsive disorder. J Neural Transm. 2012;119(10): 1077-1083.

135. Mukhopadhyay S, Fineberg NA, Drummond LM, et al. Delayed sleep phase in severe obsessive-compulsive disorder: a systematic case-report survey. CNS Spectr. 2008;13(5):406-413.

136. Muller J, Roberts JE. Memory and attention in obsessive-compulsive disorder: a review. J Anxiety Disord. 2005;19(1):1-28.

137. Schmidtke K, Schorb A, Winkelmann G, Hohagen F. Cognitive frontal lobe dysfunction in obsessive-compulsive disorder. Biol Psychiatry. 1998;43(9):666-673.

138. Penadés R, Catalán R, Rubia K, Andrés S, Salamero M, Gastó C. Impaired response inhibition in obsessive compulsive disorder. Eur Psychiatry. 2007;22(6):404-410.

139. Penadés R, Catalán R, Andrés S, Salamero M, Gastó C. Executive function and nonverbal memory in obsessive-compulsive disorder. Psychiatry Res. 2005;133(1):81-90.
140. Paavonen EJ, Raikkonen K, Lahti J, et al. Short sleep duration and behavioral symptoms of attention-deficit/hyperactivity disorder in healthy 7- to 8-year-old children. Pediatrics. 2009;123(5): e857-e864.

141. Golan N, Shahar E, Ravid S, Pillar G. Sleep disorders and daytime sleepiness in children with attention-deficit/hyperactive disorder. Sleep. 2004;27(2):261-266.

142. Gruber R, Grizenko N, Schwartz G, Bellingham J, Guzman R, Joober R. Performance on the continuous performance test in children with ADHD is associated with sleep efficiency. Sleep. 2007; 30(8):1003-1009.

143. Khurshid KA. Relationship between Attention Deficit/Hyperactivity Disorder (ADHD) and Delayed Sleep Phase Disorder (DSPD). Mind Brain. April 10, 2012. Accepted paper.

144. Van der Heijden KB, Smits MG, Van Someren EJ, Gunning WB. Idiopathic chronic sleep onset insomnia in attention-deficit/hyperactivity disorder: a circadian rhythm sleep disorder. Chronobiol Int. 2005;22(3):559-570.

145. Baird AL, Coogan AN, Siddiqui A, Donev RM, Thome J. Adult attention-deficit hyperactivity disorder is associated with alterations in circadian rhythms at the behavioural, endocrine and molecular levels. Mol Psychiatry. November 22, 2011. doi: 10.1038/ mp.2011.149.

146. Van Veen MM, Kooij JJ, Boonstra AM, Gordijn M, Van Someren EJW. Delayed circadian rhythm in adults with attention-deficit/hyperactivity disorder and chronic sleep-onset insomnia. Biol Psychiatry. 2010;67(11):1091-1096.

147. Van der Heijden KB, Smits MG, Van Someren EJ, Ridderinkhof KR, Gunning WB. Effect of melatonin on sleep, behavior, and cognition in ADHD and chronic sleep-onset insomnia. J Am Acad Child Adolesc Psychiatry. 2007;46(2):233-241.

148. Zagar R, Bowers ND. The effect of time of day on problem solving and classroom behavior. Psychol Sch. 1983;20(3):337-345.

149. Antrop I, Roeyers H, De Baecke L. Effects of time of day on classroom behaviour in children with ADHD. Sch Psychol Int. 2005;26(1): 29-43.

150. Wirz-Justice A, Haug HJ, Cajochen C. Disturbed circadian rest-activity cycles in schizophrenia patients: an effect of drugs? Schizophr Bull. 2001;27(3):497-502.

151. Wirz-Justice A, Werth E, Savaskan E, Knoblauch V, Gasio PF, MüllerSpahn F. Haloperidol disrupts, clozapine reinstates the circadian rest-activity cycle in a patient with early-onset Alzheimer disease. Alzheimer Dis Assoc Disord. 2000;14(4):212-215.

152. Savaskan E, Schnitzler C, Schröder C, Cajochen C, Müller-Spahn F, Wirz-Justice A. Treatment of behavioural, cognitive and circadian rest-activity cycle disturbances in Alzheimer's disease: haloperidol vs quetiapine. Int J Neuropsychopharmacol. 2006;9(5):507-516.
ChronoPhysiology and Therapy

\section{Publish your work in this journal}

ChronoPhysiology and Therapy is an international, peer-reviewed, open access journal focusing on research into the cyclic variations and rhythmicity in physiological processes in the body and the research and development and optimal timing of administration of therapeutic targets to achieve improved outcomes and quality of life for the patient. The

\section{Dovepress}

manuscript management system is completely online and includes a very quick and fair peer-review system. Visit http://www.dovepress.com/ testimonials.php to read real quotes from published authors. 